Cite as: Guerin, C. (2013). Rhizomatic research cultures, writing groups and academic researcher identities. International Journal of Doctoral Studies, 8, 137-150. Retrieved from http://ijds.org/Volume8/IJDSv8p137-

150Guerin0400.pdf

\title{
Rhizomatic Research Cultures, Writing Groups and Academic Researcher Identities
}

\author{
Cally Guerin \\ University of Adelaide, Adelaide, Australia
}

cally.querin@adelaide.edu.au

\begin{abstract}
As interdisciplinary research becomes increasingly common in universities, new types of research culture appear to be developing. The doctoral students undertaking studies in this research climate are themselves increasingly diverse (Gardner, Jansujwicz, Hutchins, Cline, \& Levesque, 2012; Pearson, Cumming, Evans, Macauley, \& Ryland, 2011), coming into their studies from nontraditional pathways, from a variety of disciplinary and professional backgrounds, as well as from a range of cultural and linguistic backgrounds. Informed by interview data collected from members of doctoral writing groups, this article outlines the academic researcher identities these diverse students need to develop in order to operate effectively within rhizomatic research cultures. By considering this through the lens of Deleuze and Guattari's (1980/1988) model of rhizomatic knowledge structures, we can begin to understand how the contemporary research environment values heterogeneous, non-hierarchical, networked styles of work on research projects. The article proposes that multidisciplinary doctoral writing groups offer experiences that enable researchers to embrace the qualities of flexibility, multiplicity, collegiality, and connection and that these qualities will be of benefit to students in the current research environment.
\end{abstract}

Keywords: academic identities, doctoral writing groups, rhizomatic knowledge, interdisciplinarity, research cultures

\section{Introduction}

The current research climate in universities is one in which projects are increasingly conceived as multidisciplinary, interdisciplinary, transdisciplinary, extradisciplinary, even 'wicked' (Brown, Harris, \& Russell, 2010). One effect of this is that the traditional boundaries between disciplines seem to be weakening (Becher \& Trowler, 1989; Trowler, Saunders, \& Bamber, 2012). Within this context, the individuals working on such projects are also increasingly diverse (Gardner et al., 2012; Pearson, Evans \& Macauley, 2008; Pearson et al., 2011), coming together from nontraditional pathways in the push towards widening participation (McCallin \& Nayar, 2012; McCulloch \& Thomas, 2012; Miller \& Brimicombe, 2004), from different disciplinary and pro-

Material published as part of this publication, either on-line or in print, is copyrighted by the Informing Science Institute. Permission to make digital or paper copy of part or all of these works for personal or classroom use is granted without fee provided that the copies are not made or distributed for profit or commercial advantage AND that copies 1) bear this notice in full and 2) give the full citation on the first page. It is permissible to abstract these works so long as credit is given. To copy in all other cases or to republish or to post on a server or to redistribute to lists requires specific permission and payment of a fee. Contact Publisher@InformingScience.org to request redistribution permission. fessional backgrounds (Adkins, 2009; Boud \& Tennant, 2006; Costley \& Lester, 2012), and from different cultural and linguistic backgrounds (Lee \& Danby, 2012; Rizvi, 2010; RobinsonPant, 2010).

As the current research climate changes, so too do the kinds of doctoral graduates we need to produce who are equipped to negotiate that climate effectively. What 
kind of academic and researcher identities are best suited to this research setting? How can postgraduates position themselves in relation to this environment? On the one hand, $\mathrm{PhD}$ students must still develop deep knowledge of their topic and learn competencies in "thinking like a ... [statistician, microbiologist, ethicist, etc.]" (Schön, 1987, p. 39); on the other, researchers are now expected to be adaptable, flexible, and capable of smooth transitions across disciplinary boundaries as they collaborate on projects with colleagues. Invoking a Bernsteinian framework, Adkins (2009, p. 168) considers the implications of the "weakening classifications between disciplines" in the push towards increasing interdisciplinarity in postgraduate research programs. She points out that, in the current research climate,

The link between the form and content of knowledge and the relationships that form around that knowledge, then, turns on the greater level of flexibility and fluidity required for research that is oriented to using whatever knowledge resources are required to address a particular research problem. The relationships must take their cue from the nature of the knowledge required rather than those prescribed through strong disciplinary identities. (2009, p. 173)

Thus, academic researchers need to be able to think and work with different mindsets from those that have served them well in the past.

As an alternative to Adkins' Bernsteinian approach, the current study conceptualizes a research climate characterized by flexibility and fluidity through the lens of Deleuze and Guattari's (1980/1988) model of the rhizome. Against this background, I suggest that the principles of connection, heterogeneity, and multiplicity encountered in today's rhizomatic academic networks are central to understanding what kinds of research and researchers will be needed by the academy. This article explores the implications of such a research environment for the academic researcher identities produced through doctoral education. Drawing on the reflections of members of multidisciplinary doctoral thesis writing groups, this article offers a characterization of the kinds of academic researcher identities that might be well suited to working in such rhizomatic research environments.

\section{Literature Review}

\section{Rhizomes, Networks and Research Cultures}

In the Introduction to their seminal work, A Thousand Plateaus: Capitalism and Schizophrenia (1980/1988), Deleuze and Guattari contrast the possibilities of arboreal and rhizomatic knowledge structures. They characterize traditional knowledge structures as "arboreal", comprising a "pivotal taproot" that leads to the flowering of knowledge that grows out of that singular, unified entity (Deleuze \& Guattari, 1980/1988, p. 5). Such knowledge is constructed as centralized and modelled on linear progress; it is perceived as building in one direction, moving according to a fixed order; it categorizes and classifies; and, importantly, it is hierarchical. Against this is set the model of the rhizome, which spreads horizontally in all directions. This alternative model characterizes knowledge as multiple, non-hierarchical, proliferating, and non-dualistic. Rhizomatic knowledge is based on "Principles of connection and heterogeneity; any point of a rhizome can be connected to any other, and must be" (Deleuze \& Guattari, 1980/1988, p. 7). Further, "a rhizome has no beginning or end; it is always in the middle, between things, intermezzo" (Deleuze \& Guattari, 1980/1988, p. 25).

Breaking even further from the conceptualization of knowledge as arboreal, Deleuze and Guattari go on to develop the metaphor of networks, which becomes central to their theory: "There are no points or positions in a rhizome, such as those found in a structure, tree, or root. There are only lines" (Deleuze \& Guattari, 1980/1988, p. 8). The network connects every node to every other 
node in every direction with no particular beginning or ending, forcing us to notice the dynamism of the movement between nodes, between ideas. These connections, these "lines of flight" (Deleuze \& Guattari, 1980/1988, p. 21), are possible in any direction. Importantly, however, it is not flight from something; rather, the flight indicates movement between nodes. Thus, it is the coming and going, the occupation of the space in between, that matters, rather than an attempt to reach some kind of endpoint; after all, "a rhizome may be broken, shattered at a given spot, but it will start up again on one of its old lines, or on new lines" (Deleuze \& Guattari, 1980/1988, p. 9).

From this it is possible to take a number of concepts in order to understand research cultures today. Most importantly, the nature of multi/inter/trans/extradisciplinary research requires a notion of knowledge that feeds in from different directions, but is not hierarchical - the economist's knowledge doesn't override that of the epidemiologist in a public health project; the statistician's knowledge works alongside the biologist's knowledge to enhance interpretation of the data. The diverse, heterogeneous kinds of knowledge can be used in multiple contexts, and the possible combinations are (almost?) limitless. What is of interest is how various forms of knowledge can inform each other - that is, what happens when previously separate ideas are connected with each other?

Rather than seeking a single, unified truth as one might if working according to an arboreal model of knowledge, the rhizome model forces recognition of the contingent and temporary nature of what is discovered at those nodal meeting points, forces understanding that what we learn continues to move in new, often unpredictable, directions, asking where else our thinking can move along these lines of flight. In effect, this alternative model acts as a license to try out new combinations of ideas. Thus, a rhizomatic research culture is characterized by heterogeneity, multiplicity, proliferation, flexibility, non-linearity, connection and non-hierarchical networks.

If the rhizome metaphor is taken as a model for the kind of knowledge and the kind of research environment for which our $\mathrm{PhD}$ students are preparing, what then are the qualities and characteristics they'll need in order to be able to negotiate that research environment effectively?

\section{Rhizomes and Doctoral Identities}

The rhizome metaphor developed by Deleuze and Guattari is starting to be applied to educational research (see, for example, Grellier, 2013; Le Grange, 2011; Smagorinsky, Augustine, \& Gallas, 2006) and more specifically to investigations of doctoral experiences. Some limited excursions into action research in education have used a Deleuzian model of the rhizome to conceptualise an alternative to linear notions of growth and development in doctoral students (Amorim \& Ryan, 2005; Ryan, Amorim, \& Kusch, 2010). In another study, Taylor, Downs, Baker, and Chikwa (2011, p. 194) mobilize the concepts of the rhizome and assemblage to understand the doctoral experience:

The rhizome seemed a useful concept with which to explore the ways in which the doctoral journey opens its participants to multiple, iterative and heterogeneous ways of knowing, becoming and telling. In doing so, we see the rhizome as a means to contest academic accounts which construct the doctoral journey as a linear process.

These initial ventures into the territory mark the beginnings of what promises to be an insightful addition to the field of doctoral education.

To date this discussion has not connected Deleuze and Guattari's rhizome model to research cultures and academic identities; in particular, this paper explores how academic and researcher identities, or "academicity" (Petersen, 2007), in rhizomatic research environments can be developed during doctoral studies, in particular through participation in writing groups (Barnacle, 2005; Barnacle \& Mewburn, 2010; Devos, 2004). Through this approach, I seek to consider what 
kinds of identities, what characteristic ways of thinking and behaving, today's research students can take up that will position them to operate effectively in the research cultures of tomorrow.

This discussion draws on broadly sociocultural approaches that regard identity as discursively constituted, as formed and performed socially, not simply something existing 'inside' the individual. This aligns with Butler's (1993) notion that there is no essential 'identity'; rather, identity is a discursive performativity that is iterated and reiterated. Identity is also closely linked to knowledge, in that part of who we are is what we know about. In the process of learning how to do something, we become capable of performing that task or skill; thenceforth it is possible to adopt an identity to go with that behaviour/performance (Baker \& Lattuca, 2010). Therefore, as doctoral students learn new skills and knowledge, their sense of who they are consequently changes. Thus, identity is partly defined internally by our sense of ourselves (our values, knowledge, skills, and behaviors) and partly externally by the community surrounding us (providing recognition of how we appropriately or successfully embody those values, knowledge, skills, and behaviours). This latter is what might be understood in Althusser's terms as interpellation (1970/2008, p. 48); that is, one is 'hailed' into being as an academic or researcher by others, and in recognising oneself as the subject of that hailing and responding - or turning around - to that call, the identity is assumed.

Academic and researcher identities, then, are demonstrated in how one speaks, reads, writes, behaves, and thinks about research, teaching, and administration (Brew, Boud, \& Namgung, 2011; Petersen, 2007). These demonstrations can be observed:

- in seminars, conference presentations, lectures, tutorials and laboratory demonstrations;

- in reading critically, and in what one chooses to read;

- in how one writes, for which audience and where it is published;

- in how one gives and receives feedback on ideas, on writing;

- in how one interacts with and behaves towards peers, supervisors, and other academics (that is, in terms of collegiality and autonomy);

- in how one establishes and defends knowledge claims, in what questions are considered worth asking and the answers worth having; and

- in one's relations to inanimate objects, such as computers, books, library access cards, lab equipment, room keys.

(Barnacle \& Mewburn, 2010; Kamler \& Thomson, 2006)

Those identities are also exhibited in performances of what is regarded as appropriate and competent and what is to be avoided as 'unscholarly' or beyond the bounds of the discourse community. Obviously, this is not uniformly consistent throughout academia: what is regarded as robust and rigorous debate in one seminar room might be considered overly combative and undermining in another; what is accepted as a valid research method or legitimate evidence in one field may be impossible in another. Nevertheless, there would seem to be significant commonalities shared by the vast majority of university scholars that allow them to work together effectively across disciplinary and national borders, as attested by the enormous number of interdisciplinary projects and international conferences and journals to which those scholars contribute.

But many of the rules of this game can remain opaque to novice researchers. How can we help doctoral candidates learn all this in order to operate effectively within rhizomatic research cultures? This article suggests that participation in a multidisciplinary writing group is one strategy that seems to offer some useful benefits in this respect. It is well established that $\mathrm{PhD}$ students learn a great deal from their peers (Boud \& Lee, 2005): candidates in interdisciplinary programs often rely on the knowledge of their peers as an important supplement to faculty advisers (Gardner et al., 2012), and writing groups provide an important forum in which academic identities can 
be forged (Lee \& Boud, 2003). The investigation here explores what writing group members learn from their peers (about research and about themselves) that will be useful in a rhizomatic research culture, with a particular focus on what they gain from participating in the disciplinary diversity embodied in multidisciplinary doctoral writing groups.

\section{Method}

The current discussion forms part of a larger research project into the benefits and effects of doctoral writing groups, some of which has been reported elsewhere (Guerin et al., 2012). Semistructured group interviews were conducted with participants of four multidisciplinary doctoral writing groups during their usual meeting times. Members were invited to reflect on their experiences of being involved in a doctoral writing group in general, and more specifically in relation to the disciplinary diversity within the group.

The questions guiding the broader interviews are presented in the Appendix, and the results reported here draw from the responses to Question 4 and related comments. The focus here is on the broader research context and the identities produced in the writing groups, whereas other parts of the project have been more centred on the influence of cultural and linguistic diversity in the writing group. Given the nature of semi-structured interviews, participants were encouraged to follow their own trains of thought in a conversational manner, so that the questions became a guide to topics to be covered rather than being asked strictly in order. The group interview was appropriate because, as in a focus group format, group discussion allows individuals "to react to and build on the responses of other group members" (Stewart, Shamdasani, \& Rook, 2007). This in turn facilitates an ethnographic mode of research which, in this study, provides insight into the kind of research culture the participants work in and contribute to in the writing groups as a microcosm of their broader research cultures (Denzin \& Lincoln, 2005). By working together in the interview, the members of the group develop a picture of their shared understandings (or their differences of opinion) of what they achieve together in the writing group; while they are doing this, the relationships operating between group members can also be observed by the researcher as a demonstration of the culture they are in the process of describing (Patton, 2002). Together this allows for both semantic and latent interpretations of the data (Braun \& Clarke, 2006 As would be hoped in such research, more emerged from the interviews than was originally anticipated, thus leading to reflection on the researcher's part about what these findings might mean for research cultures and identities.

The interviews were audio-recorded and transcribed by the interviewer. Written comments were also collected at the time of the interviews, and some members of the groups who were unable to be present at the face-to-face interview provided written comments separately based on the ques-

tions listed in the Appendix. The interview transcriptions and written comments were subjected to a recursive process of inductive analysis (Braun \& Clarke, 2006; Patton, 2002 ) to establish recurring themes (Flick, 2009; Patton, 2002). The credibility of findings was measured against participant checking (Patton, 2002), which included one of the groups working with the researcher to co-write an autoethnographic article based on their own interview data (Guerin et al., 2012). 


\section{Participants}

Details of participants are summarized in Table 1.

Table 1. Participant details

\begin{tabular}{|l|l|}
\hline Gender & Disciplinary background \\
\hline $\begin{array}{l}\text { Humanities \& Social Sciences } \\
\text { 6umSS) }\end{array}$ & English, politics, education, art history, architecture \\
\hline $\begin{array}{l}\text { Public Health } \\
7 \text { women, 1 man }\end{array}$ & $\begin{array}{l}\text { economics, ethics/law, epidemiology, statistics, } \\
\text { pharmacy, occupational health and safety, health } \\
\text { policy development }\end{array}$ \\
\hline $\begin{array}{l}\text { Bioscience } \\
8 \text { women, 10 men }\end{array}$ & forensic biology, entomology, evolutionary biology \\
\hline $\begin{array}{l}\text { Health Sciences } \\
\text { 3 women, 4 men }\end{array}$ & obstetrics and gynaecology, paediatrics, genetics \\
\hline
\end{tabular}

All four writing groups had originally been established by the researcher (an academic developer employed by the university) with the intention of getting the groups started and then leaving them to be managed by participants; the researcher had facilitated the first five sessions for each group, and then the students continued to meet independently. At the time of the interviews, the HumSS group had been meeting fortnightly for twelve months; with only minor interruptions during holiday periods, the Public Health group had been meeting fortnightly for almost two years; the Bioscience group had been meeting fortnightly for nine months; and the Health Sciences group had been meeting fortnightly for twelve months. In all groups attendance levels were variable, but participants appeared to regard themselves as belonging to an organized group that met regularly, even if they themselves did not attend every meeting in person. For the project under discussion here, four members contributed from the HumSS group, eight from the Public Health group, ten from the Bioscience group, and six from the Health Sciences group (in total, 28 of the 39 writing group members participated in the interviews and provided written comments - some regular attendees were absent on the occasion of the group interviews).

\section{Results}

A number of themes emerged from the participants' responses to questions relating to the benefits of the diversity of their group membership; their insights are then used to inform understanding of how these experiences influence their emerging academic researcher identities, how this in turn influences their concepts of how to perform those identities, and how these elements might work together to their advantage in rhizomatic research cultures. The themes discussed here are networking for information; thinking critically; communicating with a broader audience; and connecting to broader learning. Keeping in mind that identities are demonstrated in how we think and behave, these activities (networking, thinking, communicating, and connecting) are linked here to the key characteristics of rhizomatic research cultures as listed above, namely, networks, connection and lines of flight; multiplicity and proliferation; non-linearity and non-hierarchical relations of knowledge; flexibility; and heterogeneity. In this way can begin to see how these students are not only starting to notice what is valuable to them in this multidisciplinary context, but also that they are constructing a sense of themselves as competent within that context: they are beginning to exhibit and perform identities that can effectively negotiate rhizomatic research cultures. 


\section{Networking for Information}

One element that became apparent from the interviews was the pragmatic advantage of having access to more information for one's own project through the connections made with researchers beyond one's own immediate circle of colleagues. A participant in the Bioscience group provided a clear instance of this:

A lot of the time there are people in this building that are using the same programs as you, but no one else in your lab group is. And unless you know those people, you don't know to go to them and ask if you have a problem ... So it's really good to have groups like this one that do cross the boundaries between lab groups to find out these skills. (Bioscience)

Networking can, of course, be enormously beneficial for students in all sorts of doctoral programs (see, for example, Harman, 2004, on Cooperative Research Centres; Pearson et al., 2008, on the massification of doctoral education; Pilbeam \& Denyer, 2009, on Business and Management students; Boud \& Tennant, 2006, on professional doctorates; and Hopwood, 2010, on social network theory and agency), and it is necessary for researchers seeking to extend their knowledge and project capacity beyond their immediate research groups. For students entering into rhizomatic research cultures, a collegial attitude of collaborative sharing of knowledge and information at this early stage in their careers is to be encouraged. A rhizomatic research culture requires individuals to see the benefits of reaching out along lines of flight to make connections in order to build knowledge across disciplinary boundaries.

\section{Thinking Critically}

Participants reported that engaging in an interdisciplinary writing group aided the development of their own critical thinking when they attempted to critique writing from fields outside their own area of expertise. For example, one member of the HumSS group explained:

I've heard a few other people saying, you know, "I'm not going to sit down and read somebody else's work from a different discipline or faculty - that'd just be a waste of time." But I've just learnt so much! And I think learning to critique a paper that hasn't got your content helps you to think, helps you structure your thinking in a certain way... (HumSS)

Opportunities to work across disciplines can thus develop generic and transferable skills that can be applied to other areas of intellectual endeavour. Stepping outside of one's own discipline has a two-way effect: not only does it allow for greater knowledge gain in related areas, but it also simultaneously builds the capacity for critical thinking in one's own discipline. This is, of course, a key skill and is frequently discussed in the literature and 'how to' books on doctoral pedagogy (amongst recent examples see Denholm \& Evans, 2006; Evans, Gruba \& Zobel, 2011; Paltridge \& Starfield, 2007; Petre \& Rugg, 2010; Thomson \& Walker, 2010; Wallace \& Wray, 2006) but is not always easily achieved. When it comes to engaging with concepts and materials across disciplinary boundaries in a rhizomatic research culture, the capacity to think critically becomes even more complex; equally, this capacity is perhaps even more important when researchers are required to navigate competing paradigms or methodologies as they work across potentially disparate fields of research. Such capacities require flexibility in thinking and the ability to see new connections between heterogeneous ideas.

\section{Communicating with a Broader Audience}

Writing about research in an interdisciplinary and multicultural setting was regarded by the participants as a means of not only sharpening their ability to interrogate their own assumptions, but 
also developing their skills in communicating complex ideas to a broad audience. This was directly acknowledged as an asset in the contemporary academic setting.

In my opinion, the diversity has a strong influence in this group... For the presenter it means that his or her work has to be explained very well given the "lay audience", which I guess is generally an important aspect in academia. (Public Health)

It doesn't even matter if you don't fully understand the subject they're writing on because it's all about whether it's interesting, whether it conveys ... a message. (Bioscience)

It's nice working with people who don't study what I study, because they would fill in gaps in knowledge ... People here, like, they don't understand, it's my fault they don't understand, so I need to address that more. (HumSS - bold indicates emphasis by speaker)

So I think what we're learning to do is, when we do our own work, there's a lot that's implicit to us, and then we come in and share it with somebody else and we have to be more explicit [murmurs of assent from others]. We have to explain things more and structure things better, because of the people who are not so familiar with the work ... so that's been very useful. (HumSS - bold indicates emphasis by speaker)

Working with others in interdisciplinary writing groups has brought into focus the requirement of communicating to broad audiences and was clearly regarded as a specific advantage of participation in such a writing group. The concomitant awareness of a writer's audience is invaluable in research writing (Hyland, 2008) and is essential for those collaborating on projects across disciplines, where it is necessary to consider the levels of background knowledge and expertise of one's readers and co-researchers. Researchers are increasingly expected to be accountable to a broader audience and to be capable of communicating the significance and content of their work beyond their immediate discipline. This is demonstrated in all sorts of ways: government and industry funding bodies making decisions on the research they will support are rarely composed of experts in the precise area of the project under consideration; the impact of some research projects is dependent on effective dissemination to community groups; journals in the Cell group now require that authors provide Wikipedia entries along with submissions; and the growing success of the Three Minute Thesis competition in Australia and beyond is specifically focused on training PhD students to communicate complex doctoral research to the general public. Again, the rhizomatic research world requires such lines of flight towards heterogeneous audiences and bodies of knowledge beyond the traditional disciplinary boundaries, making connections between disparate knowledge communities.

\section{Connecting to Broader Learning}

Participants also referred to the benefits of the broader learning they gained from working with students from other disciplines in the writing groups, seeing the diversity in the projects as an opportunity to develop knowledge in areas related to their own interests but reaching out into new trajectories.

It's good to see what other people are doing and learn about something ... Seeing there's something else out there helps you think outside the box a little bit more. (Bioscience)

I'm reading all the work that these people do and I'm actually learning new things that I normally would not read about and I'm always asking questions, and it's interesting for me personally. (Health Sciences) 
By being exposed to a number of research projects in different fields, you broaden your understanding of other research areas which is vital if you wish to be a well-rounded academic who has a good understanding of other fields. Nowadays, research is often multi-disciplinary and so developing an understanding of other areas is important. (Public Health)

One modest participant explained that "I'm interested in everybody else's work, and sometimes they are in mine..." (HumSS)

The stimulation of learning about projects beyond their own immediate topics was appreciated as part of their doctoral education, but participants were also aware of how this helped them prepare for research careers beyond the current project. The heterogeneity of the participants' projects encouraged intellectual lines of flight in new and unexpected directions, developing an appreciation of the research cultures outside their own immediate projects. This in turn promoted a sense of the interconnected nature of knowledge and an understanding of how their own work might fit into a bigger picture of the academy, a conceptual achievement that many students struggle with (Bitchener \& Basturkmen, 2006) on the way to what Trafford and Leshem (2009, p. 305) describe as "doctorateness".

One student summed this up succinctly:

I realise that every knowledge/area of interest is connected/related to others. So, through the group I learn to be familiar with/to get used to the multidisciplinary concept, which will be invaluable for my professional development. (Public Health)

Thus, the researcher learns to think along lines of flight that move in multiple directions, rather than being limited to a single area of expertise.

\section{Discussion}

From the interviews reported above, then, what can we learn about the academic and researcher identities exhibited by doctoral students operating in complex multi/inter/trans/extradisciplinary research environments, as exhibited and performed in the microcosm of their writing groups? A number of characteristic behaviours and ways of thinking about their work and their role in the academy emerge from the data, pointing towards the kinds of identities these students are developing. Firstly, the participants in the multidisciplinary doctoral writing groups appear to be open to new ideas. Secondly, their experiences in the writing groups have promoted their skills in providing constructive feedback in peer review and the capacity to engage effectively with unfamiliar work. Interestingly, most were remarkably modest about their own achievements, which appears to be partly related to the ways in which they see themselves as always learning, as becoming scholars, rather than as established experts. This would seem to emerge from being positioned in a particular relationship to the content of the writing - because they are not authorities, because they are reading new, unfamiliar material, they do not feel obliged to know everything about the topic. Nevertheless, they are also confident that their opinions are worth considering and that others can learn from them; consequently, they develop appropriate levels of confidence alongside the modesty they express more overtly. Further, their comments about what they are learning also indicate that they see themselves as networked, as linked in, and as being 'in process' rather than

finished or complete. Finally, their reflections on the experience of engaging in peer review in the writing group sessions reveal their recognition of the value of collaboration, of collegial work, and of forming alliances across peer networks. All these attitudes and ways of being are central to the identities these students perform.

In an attempt to reflect on the kinds of academic researcher identities emerging in the doctoral students interviewed here, I propose a tentative description of how such identities might be dis- 
tinguished from an older mode of being that might have been more suited to traditional disciplinary structures (summarized in Table 2). Although the 'silo' discipline may in reality be something of a myth, the concept of distinct, separate disciplines operating according to traditionally 'arboreal' knowledge structures serves as a useful reference point from which to articulate the kinds of identities required by a rhizomatic research culture.

Table 2. Academic researcher identities: silo disciplines and rhizomatic research cultures

\begin{tabular}{|l|l|}
\hline Silo Discipline & Rhizomatic Resarch Culture \\
\hline expert & always learning \\
\hline core content that is known & open to new knowledge \\
\hline predictable content & unknown material \\
\hline separate & networked, connected \\
\hline lone researcher & collaborative, collegial \\
\hline clear opinions & tentative \\
\hline confident & modest \\
\hline fixed, endpoint & flexible, in between \\
\hline homogeneous & heterogeneous \\
\hline singularity, either/or & multiplicity, both/and \\
\hline telling & (actively) listening \\
\hline
\end{tabular}

In a silo discipline, researchers could perhaps be characterized as experts in fields where the core content knowledge is agreed and known by other experts in the field; they deal with reliable content in predictable contexts; they might conceive of their work as separate from other disciplines, sometimes tending to work as lone researchers (particularly in the Humanities and Social Sciences). Clear and confident opinions can be expressed in this arboreal world where knowledge moves uni-directionally towards a single endpoint of truth. A researcher identity here inclines towards homogeneity and singularity in the quest for fixed, either/or answers to the field's questions.

By contrast, those working in rhizomatic research cultures need to be in a state of constant learning, of being open to new knowledge, and capable of approaching unknown material. They are networked and connected to others, attuned to working in collaborative, collegial ways. Their knowledge claims remain tentative in full awareness of the vast array of what might seep into their field of focus from surrounding research. This in turn encourages modesty and humility in what can be said; listening actively is valued, as is the capacity for flexibility and occupation of the space in between (Deleuze \& Guattari, 1980/1988). Thus, the researcher inclines towards heterogeneity and multiplicity in the search for both/and answers.

\section{Conclusion}

As research cultures continue to adapt to the changing needs of our societies, so too do the academic researcher identities of those who work within those cultures. This paper has considered the implications of characterizing the current research culture as 'rhizomatic' and the consequent academic researcher identities doctoral students need to develop in order to operate effectively within such a research climate. Interviews with members of multidisciplinary doctoral writing 
groups suggest that such writing groups provide an ideal environment in which to develop many of the traits of flexibility, multiplicity, collegiality, and connection that might be of benefit to academic researchers in heterogeneous, non-hierarchical, networked rhizomatic research cultures. While these qualities in academic researcher identities are by no means entirely new, they are the qualities that are likely to be prized by the complex and diverse research environments new researchers are entering today. Perhaps what we are seeing in the accounts from doctoral students in these writing groups is the emergent embodiment of the nomadic scholar poised to follow Deleuze and Guattari's (1980/1988, p. 24) exhortation: "Don't sow, grow offshoots!'”

\section{Appendix}

\section{Reflections on Thesis Writing Group Experience}

The following questions formed the basis of the open-ended, semi-structured group discussions.

1. How has your writing changed since the TWG commenced?

2. In what ways has the TWG supported you professionally?

3. In what ways has the TWG supported you personally?

4. How has the national and disciplinary diversity contributed to your development? (e.g. different language groups, reading and critiquing writing on different topics, etc).

5. How has the TWG contributed to your development as a researcher?

6. Is the group a useful place for learning academic behaviours (eg how to provide useful feedback to colleagues, etc). Please elaborate and provide examples if possible.

7. How important is the writing group for making you feel like a member of the academic community?

8. What makes you keep coming back to meetings?

9. What was the 'best moment' for you in relation to this group?

10. If there have been times when you felt that you weren't getting enough out of the group, can you explain why this was?

11. Have you ever been involved in a study group previously? Please elaborate.

\section{References}

Adkins, B. (2009). PhD pedagogy and the changing knowledge landscapes of universities. Higher Education Research \& Development, 28(2), 165-177.

Althusser, L. (2008). Ideology and ideological state apparatuses. On Ideology, (pp. 1-60). (B. Brewster, Trans.). London: Verso. (Originally published in 1970.)

Amorim, A., \& Ryan, C. (2005). Deleuze, action research and rhizomatic growth. Educational Action Research, 13(4), 581-593.

Baker, V. L., \& Lattuca, L. R. (2010). Developmental networks and learning: Toward an interdisciplinary perspective on identity development during doctoral study. Studies in Higher Education, 35(7), 807827.

Barnacle, R. (2005). Research education ontologies: Exploring doctoral becoming. Higher Education Research \& Development, 24(2), 179-188.

Barnacle, R., \& Mewburn, I. (2010). Learning networks and the journey of 'becoming doctor'. Studies in Higher Education, 35(4), 433-444.

Becher, T., \& Trowler, P. (1989). Academic tribes and territories: Intellectual enquiry and the cultures of disciplines (2nd ed.). Buckingham, UK: Open University \& Society for Research into Higher Education. 
Bitchener, J., \& Basturkmen, H. (2006). Perceptions of the difficulties of postgraduate L2 thesis students writing the discussion section. Journal of English for Academic Purposes, 5, 4-18.

Boud, D., \& Lee, A. (2005). 'Peer learning' as pedagogic discourse for research education. Studies in Higher Education, 30(5), 501-516.

Boud, D., \& Tennant, M. (2006). Putting doctoral education to work: Challenges to academic practice. Higher Education Research \& Development, 25(3), 293-306.

Braun, V., \& Clarke, V. (2006) Using thematic analysis in psychology. Qualitative Research in Psychology, 3(2), 77-101.

Brew, A., Boud, D., \& Namgung, S. U. (2011). Influences on the formation of academics: The role of the doctorate and structured development opportunities. Studies in Continuing Education, 33(1), 51-66.

Brown, V. A., Harris, J. A., \& Russell, J. Y. (Eds). (2010). Tackling wicked problems through the transdisciplinary imagination. Abingdon, UK: Earthscan.

Butler, J. (1993). Bodies that matter: On the discursive limits of 'sex'. New York and London: Routledge.

Costley, C., \& Lester, S. (2012). Work-based doctorates: Professional extension at the highest levels. Studies in Higher Education, 37(3), 257-269

Deleuze, G., \& Guattari, F. (1988). A thousand plateaus: Capitalism and schizophrenia. Trans. B. Massumi. London: Athlone Press. (Original work published 1980.)

Denholm, C. \& Evans, T. (Eds.). (2006). Doctorates downunder: Keys to successful doctoral study in Australian and New Zealand. Camberwell, VIC: ACER.

Denzin, N. K., \& Lincoln, Y. S. (Eds). (2005). The SAGE handbook of qualitative research. (3rd ed.). Thousand Oaks \& London: Sage.

Devos, A. (2004). The project of self, the project of others: Mentoring, women and the fashioning of the academic subject. Studies in Continuing Education, 26(1), 67-80.

Evans, D., Gruba, P., \& Zobel, J. (2011). How to write a better thesis. Carlton, Vic: Melbourne University Press.

Flick, U. (2009). An introduction to qualitative research (4th ed.) Thousand Oaks \& London: Sage.

Gardner, S. K., Jansujwicz, J., Hutchins, K., Cline, B., \& Levesque, V. (2012). Interdisciplinary doctoral student socialization. International Journal of Doctoral Studies, 7, 377-394. Retrieved from http://ijds.org/Volume7/IJDSv7p377-394Gardner0385.pdf

Grellier, J. (2013). Rhizomatic mapping: Spaces for learning in higher education. Higher Education Research and Development, 32(1), 83-95.

Guerin, C., Xafis, V., Doda, D.V., Gillam, M., Larg, A., Luckner, H., Jahan, N., Widayati, A. \& Xu, C. (2013) Diversity in collaborative research communities: A multicultural, multidisciplinary thesis writing group in Public Health. Studies in Continuing Education 35(1): 65-81.

DOI:10.1080/0158037X.2012.684375.

Harman, K. M. (2004). Producing 'industry-ready' doctorates: Australian Cooperative Research Centre approaches to doctoral education. Studies in Continuing Education, 26(3), 387-404

Hopwood, N. (2010). A sociocultural view of doctoral students' relationships and agency. Studies in Continuing Education, 32(2), 103-117.

Hyland, J. (2008). Disciplinary voices: Interactions in research writing. Journal of English Text Construction, 1(1), 5-22.

Kamler, B., \& Thomson, P. (2006). Helping doctoral students write: Pedagogies for supervision. New York and London: Routledge.

Lee, A., \& Boud, D. (2003). Writing groups, change and academic identity: Research development as local practice. Studies in Higher Education, 28(2), 187-200. 
Lee, A., \& Danby, S. (Eds). (2012). Reshaping doctoral education: International approaches and pedagogies. London: Routledge.

Le Grange, L. L. L. (2011). Sustainability and higher education: From arborescent to rhizomatic thinking. Educational Philosophy and Theory, 43(7), 742-754. DOI: 10.1111/j.1469-5812.2008.00503.x

McCallin, A., \& Nayar, S. (2012). Postgraduate research supervision: A critical review of current practice. Teaching in Higher Education, 17(1), 63-74.

McCulloch, A., \& Thomas, L. (2012). Widening participation to doctoral education and research degrees: A research agenda for an emerging policy issue. Higher Education Research \& Development, 32(2), 214-227. DOI:10.1080/07294360.2012.662630

Miller, N., \& Brimicombe, A. (2004). Mapping research journeys across complex terrain with heavy baggage. Studies in Continuing Education, 26(3), 405-417.

Paltridge, B., \& Starfield, S. (2007). Thesis and dissertation writing in a second language: A handbook for supervisors. Abingdon, UK: Routledge.

Patton, M. Q. (2002). Qualitative research and evaluation methods. (3rd ed.) Thousand Oaks \& London: Sage.

Pearson, M., Evans, T., \& Macauley, P. (2008). Growth and diversity in doctoral education: Assessing the Australian experience. Higher Education, 55, 357-372.

Pearson, M., Cumming, J., Evans, T., Macauley, P., \& Ryland, K. (2011). How shall we know them? Capturing the diversity of difference in Australian doctoral candidates and their experiences. Studies in Higher Education, 36(5), 527-542 .

Petersen, E. B. (2007). Negotiating academicity: Postgraduate research supervision as category boundary work. Studies in Higher Education, 32(4), 475-487.

Petre, M., \& Rugg, G. (2010). The unwritten rules of PhD research. (2nd ed.). Maidenhead, UK: Open University Press.

Pilbeam, C., \& Denyer, D. (2009). Lone scholar or community member? The role of student networks in doctoral education in a UK management school. Studies in Higher Education, 34(3), 301-318.

Rizvi, F. (2010). International students and doctoral studies in transnational spaces. In M. Walker \& P. Thomson (Eds), The Routledge doctoral supervisor's companion: Supporting effective research in education and the social sciences (pp. 158-70). London: Routledge.

Robinson-Pant, A. (2010). Internationalisation of higher education: Challenges for the doctoral supervisor. In M. Walker \& P. Thomson (Eds), The Routledge doctoral supervisor's companion: Supporting effective research in education and the social sciences (pp. 147-57). London: Routledge.

Ryan, C., Amorim, A. C., \& Kusch, J. (2010). Writing ourselves reflectively. Reflective Practice: International and Multidisciplinary Perspectives, 11(2), 115-125.

Schön, D. A. (1987). Educating the reflective practitioner: Toward a new design for teaching and learning in the professions. San Francisco, CA: Jossey-Bass.

Smagorinsky, P., Augustine, S. M., \& Gallas, K. (2006). Rethinking rhizomes in writing about research. The Teacher Educator, 42(2), 87-105.

Stewart, D. W., Shamdasani, P. N., \& Rook, D. W. (2007). Focus groups: Theory and practice (2nd ed). Applied Social Research Methods Series, vol. 20. Thousand Oaks: Sage.

Taylor, C., Downs, Y., Baker, R., \& Chikwa, G. (2011). 'I did it my way': Voice, visuality and identity in doctoral students' reflexive videonarratives on their doctoral research journeys. International Journal of Research and Method in Education, 34(2), 193-210.

Thomson, P., \& Walker, M. (Eds). (2010). The Routledge doctoral student's companion: Supporting effective research in education and the social sciences. London: Routledge. 
Trafford, V., \& Leshem, S. (2009). Doctorateness as a threshold concept. Innovations in Education and Teaching International, 46(3), 305-316.

Trowler, P., Saunders, M., \& Bamber, V. (Eds). (2012). Tribes and territories in the 21st century: Rethinking the significance of disciplines in higher education (International Studies in Higher Education). Abingdon, UK: Routledge.

Wallace, M., \& Wray, A. (2006). Critical reading and writing for postgraduates. Thousand Oaks, CA: Sage.

\section{Biography}

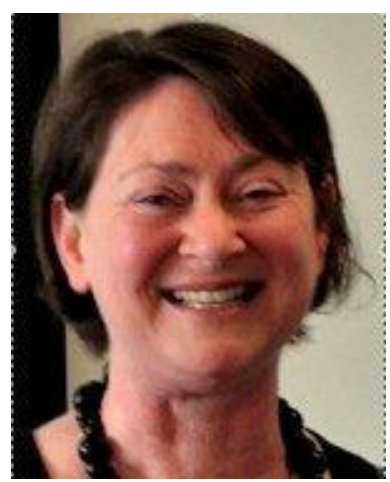

Dr Cally Guerin is a lecturer in the Discipline of Higher Education in the School of Education, Adelaide University, Australia, where she works with doctoral students and their supervisors on the development of research skills. Her research interests are in doctoral education, academic integrity and writing skills development. She is a regular contributor to the 'doctoralwriting' blog. Recent publications include: Guerin, C. \& Green, I. (forthcoming) Cultural diversity and the imagined community of the global academy. Asia Pacific Journal of Education; Guerin, C. \& Green, I. (2013) 'They're the bosses': Feedback in team supervision. Journal of Higher and Further Education; Guerin, C. \& Green, I. (2013) 'Collaborative Critique' in a supervisor development program. Innovations in Teaching and Education International; Guerin, C. et al. (2012) Diversity in collaborative research communities: A multicultural, multidisciplinary thesis writing group in Public Health. Studies in Continuing Education 35(1): 65-81; Guerin, C. \& Picard, M. (2012) Try it on: Voice, concordancing and text matching in doctoral writing. International Journal of Educational Integrity 8(2); Guerin, C., Bastalich, W. \& Green, I. (2011) Big love: Managing a team of research supervisors. In Kumar, V. \& Lee, A. (eds). Connecting the Local, Regional and International in Doctoral Education, Serdang, Universiti Putra Malaysia Press. 